Hydrol. Earth Syst. Sci., 16, 2523-2530, 2012

www.hydrol-earth-syst-sci.net/16/2523/2012/

doi:10.5194/hess-16-2523-2012

(C) Author(s) 2012. CC Attribution 3.0 License.

(c) (i)

\title{
Irrigania - a web-based game about sharing water resources
}

\author{
J. Seibert ${ }^{1,2,3}$ and M. J. P. Vis ${ }^{1}$ \\ ${ }^{1}$ Department of Geography, University of Zurich, Switzerland \\ ${ }^{2}$ Department of Physical Geography and Quaternary Geology, Stockholm University, Sweden \\ ${ }^{3}$ Department of Earth Sciences, Uppsala University, Sweden \\ Correspondence to: J. Seibert (jan.seibert@geo.uzh.ch)
}

Received: 1 February 2012 - Published in Hydrol. Earth Syst. Sci. Discuss.: 13 February 2012

Revised: 28 June 2012 - Accepted: 11 July 2012 - Published: 6 August 2012

\begin{abstract}
For teaching about collaboration and conflicts with regard to shared water resources, various types of games offer valuable opportunities. Single-player computer games often give much power to the player and ignore the fact that the best for some group might be difficult to achieve in reality if the individuals have their own interests. Here we present a new game called Irrigania, which aims at representing water conflicts among several actors in a simplified way. While simple in its rules, this game illustrates several gametheoretical situations typical for water-related conflicts. The game has been implemented as a web-based computer game, which allows easy application in classes. First classroom applications of the game indicated that, despite the simple rules, interesting patterns can evolve when playing the game in a class. These patterns can be used to discuss game theoretical considerations related to water resource sharing.
\end{abstract}

\section{Introduction}

Sharing water resources often implies compromises be found between different interests. Imparting an understanding of such situations is an important part of educating professionals that have to work with issues related to water resource collaboration and conflicts (Douven et al., 2012). Games can be a suitable tool for teaching about these interest conflicts between different water uses (Rusca et al., 2012) or raising awareness on water sharing issues (Rajabu, 2007). Different types of games are available for education. An example is the World Water Game (Deltares, 2012), where the player decides on different measures to avoid water shortages in the various regions of the world. In another game, developed by the Swiss Federal Office for the Environment (FOEN), the player can take different water management actions for a city and rural areas along a stream reach (FOEN, 2012). In some computer games, an attempt is made to be as realistic as possible. This, however, can make the game complex and, thus, less attractive and more difficult to understand (Jones, 2011). One can also note that, even in complex games, not everything is represented in a realistic way. An example is the computer game SimCity, where urban hydrology is included, but partly in an unrealistic way (Hellweger and D'Artista, 2007).

In all these games, as in many other similar computer games, the player has the power to act as a monarch. In this case, the issue is to find the right decisions for optimizing the prosperity, defined in terms of wealth for the entire society or system. In most real situations, such a single ruler is obviously unrealistic as there are many different actors who make decisions and each actor has his/her own interests. The issue, therefore, is often not only to know what the best solution for everyone on a long-term perspective would be, but also how to realize this solution in a situation where the best decision for a larger group might be different from the interests of single actors. This is especially the case in tragedy of common good (Hardin, 1968) situations, where a group of self-interested individuals deplete a shared resource. Each individual is acting rational, optimizing his/her own profit, but ultimately this overuse will result in a situation that is not beneficial to anyone on the long term.

Role-playing games are a type of game which allows for interaction between different actors. The negotiation game "Transboundary Waters Resolving Conflicts - Building Trust Negotiation Simulation" developed by J. Kuylenstierna (personal communication, 2002) is an example of a role-playing game. Here the players take on the roles of different actors 
in the negotiation of water-related issues between two countries. In this type of role-playing game, the players are not restricted to a limited number of possible actions, which can result in creative (but sometimes also unrealistic) solutions, because actions are not evaluated in a quantitative way. Such role-playing games can also be played online, which has been found to be beneficial for student learning (Maier, 2007; Varzaly and Baron, 2009).

Another type of role-playing game are games where players have limited decision options, and these decisions are evaluated in some quantitative way, which in some of the games is computer-based. Good examples are the games "River Basin Game" and "Globalization of Water Management" (Hoekstra, this issue), which are designed to demonstrate issues related to sharing a common resource in an up- and downstream setting, incorporating the concepts of water footprint and virtual water trade. These games are played in a board game-like setting and the players are limited to a certain number of actions, which are then quantitatively evaluated using a computer. The Irrigation Management Game (Burton, 1989, 1994) and another game called River Basin Game (Magombeyi et al., 2008) are other interesting examples of water resource games where negotiations between different players are central. The River Basin Game revolves around a sloping board where the downstream flow of water is represented by glass marbles, which may or may not end up in different fields for irrigation.

Here we present a new web-based game called Irrigania, which aims at representing water conflicts among farmers in a simplified way. While simple in its rules, this game illustrates several game-theoretical situations typical for waterrelated conflicts.

\section{Background on game theory}

Game theory is the mathematical analysis or modeling of the interaction between players, where the amount of payoff that a player receives is dependent on the player's own decision, as well as the decisions of the other players. Madani (2010) recently reviewed the applicability of game theory to water resource issues and concludes that game theory can help understand and resolve water conflicts. Game theory can help to comprehend the use, or often misuse, of public goods or the hindrance for cooperation. An example of an interesting theoretical illustration in this regard is the "Public Good Experiment" game. In a group of 4 participants, everybody gets $\$ 5$. The participants can choose to invest (part of) the money for the group. The total amount of invested money will be doubled and shared among the 4 participants. Since a participant only gets back half of the amount he/she invested himself/herself, the optimal strategy for each of the participants is to "free ride" on the others, i.e., to invest nothing. However, the whole group would be better off if each participant would invest all his/her money (in that case each participant would receive $\$ 10$, the Pareto optimal solution) (Ledyard, 1995).

A Nash equilibrium is a set of strategies chosen by each of the individual players, with the characteristic that none of the players can increase his/her payoff by changing strategy when all other players keep their strategy fixed (Nash, 1951). In the Public Good Experiment, for example, a player can increase his/her payoff by investing less money for the group (assuming that all other players are keeping their investment fixed). Once a player invests nothing for the group, no further improvement can be accomplished. Thus, the situation where all players invest nothing for the group is a Nash equilibrium.

However, studies have shown that people do not always behave as would be expected from pure analytical game theory (Kahneman et al., 1986). A good example is the ultimatum version of "A piece of the pie". One player gets an amount of money (x). He or she then offers part of it (y) to the other player. The other player can accept or reject the offer. If (s)he accepts, (s)he will receive y, whereas the player who made the offer earns $\mathrm{x}-\mathrm{y}$. If (s)he rejects, both players earn nothing. The optimal strategy for the receiver is to accept whatever amount (s)he gets offered. Therefore, the optimal strategy for the first player would be to offer the minimum amount that is possible. However, studies have shown that the receiver does not always play the optimal strategy, but sometimes rejects an offer (e.g., Hoffman et al., 1996; List and Cherry, 2000) to punish the other player for not offering a "fair" amount of money (Kahneman et al., 1986). As with many water-related issues, actors might behave differently than the optimal strategy, and behavioral game theory might provide a better explanation than pure analytical game theory.

A game can be repeated several times. In a repeated game, players might adapt their strategy based on the decisions of the other players in previous rounds (Camerer, 2003) as well as take into account how their strategy will affect the future decisions of other players (Osborne and Rubinstein, 1994). A player might take into account how his/her strategy could change his/her reputation. If his/her behavior is seen by the other players as selfish, they might punish him/her, possibly resulting in a bigger loss than the short-term profit.

A distinction can be made between non-cooperative games, where players cannot make any agreements, and cooperative games, where players can make (binding) agreements about the strategies they will use. Furthermore, games can be of complete or incomplete information. In a game of complete information, all players know exactly the payoff that each of the players will receive for all possible strategies till the end of the game. In a game of incomplete information, at least one of the players does not know all the payoffs. 


\section{Description of the game}

\subsection{Game idea}

Irrigania is a web-based game on the shared used of limited water resources. The idea behind the game is that there are different villages with a number of farmers in each of them. The goal for each farmer is to generate the largest net income. This, however, requires a certain amount of cooperation within the village. Each player represents one farmer in one village and has 10 fields for which he/she can decide how to use them each year. There are three options: rainfed agriculture, irrigation using river water, and irrigation using groundwater. Different costs and revenues are associated with the different types of fields (Table 1) depending on a number of variables (see Table 2 for a parameter list). While largely simplified, these costs and revenues reflect some aspects of reality. Rainfed agriculture has the lowest costs, but also less revenue than the other options. With irrigation, more can be produced both in terms of quantity and quality, which is reflected by higher revenues, but also by higher costs. In the case of river water irrigation, the cost is fixed, but the income can be reduced if the river water has to be distributed among too many fields in a village. In the case of groundwater-based irrigation, the revenue is fixed, but the costs increase if the depth to groundwater increases.

The reduction factor $k$ for revenue from river waterirrigated fields due to overuse of the river water is calculated based on the precipitation conditions and the number of river water-irrigated fields (Eq. 1, Table 1). This implies that, in a normal year, the revenue is reduced if there are on average more than 2.5 fields per farmer irrigated by river water. The reduction is linear, which means that the revenue will drop at a constant rate if there are too many river water-irrigated fields. Both for an individual farmer and also for the village as a whole, it is beneficial to use somewhat more than the 2.5 (for a normal year) fields for river water irrigation, as the drop in revenue per field is compensated by the increased number of fields. Assuming a village with five farmers and only the two alternatives, rainfed and river water irrigation for simplicity, the optimum number of fields irrigated with river water is slightly above 3 with respect to the whole village, whereas it is higher than this village-optimum value for an individual farmer as long as the average number of riverirrigated fields in the entire village does not exceed 5 (Fig. 1).

$k=\min \left[1,1-\frac{F_{\text {river }} / n-(1.5+P)}{10-(1.5+P)}\right]$

The groundwater level $g$ in year $t$, expressed as depth to groundwater, is updated based on precipitation conditions and the number of groundwater-irrigated fields (Eq. 2).

$g_{t}=\max \left[0, g_{t-1}-P-0.5+F_{\mathrm{gw}} / n\right]$

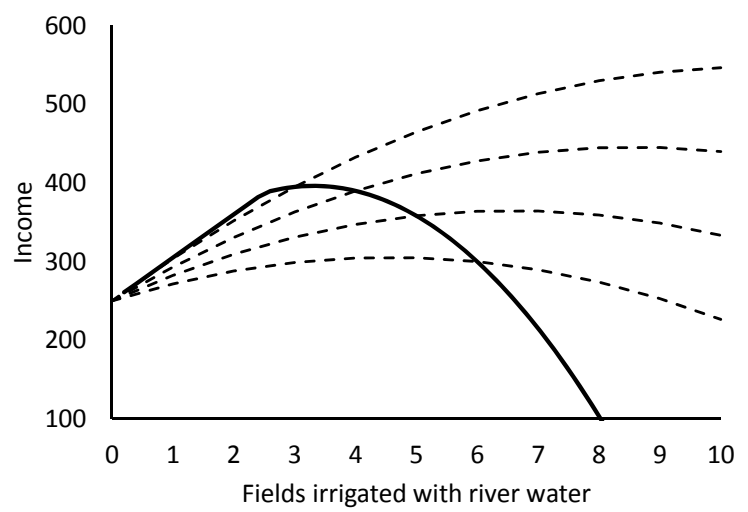

Fig. 1. Example to demonstrate the "tragedy of the common" in Irrigania. Here a village with five farmers and a normal precipitation year is assumed. Only two options, rainfed or river water irrigation, are considered for the ten fields. The black line shows the average income of the entire village per farmer as a function of the average number of river-irrigated fields and has a maximum value for an average of 3.4. The dashed lines show the income of one individual farmer as a function of the number of river-irrigated fields for different averages of river-irrigated fields for the other four farmers in the village, ranging from 3 for the upper line to 6 for the lowest line, with maximum values at 10 fields (for average field number of 3, upper line), 9 (for 4), 7 (for 5) and 5 (for 6, lowest line). The intersection of the black line with the dashed line is the income an individual farmer would have if he/she would use just as many fields as the village average; if the dashed lines is increasing to the right of the intersection point, this means that it is beneficial for an individual farmer to increase the number of river-irrigated fields by one or more.

This equation implies that under normal precipitation conditions groundwater levels will drop if there are on average more than 1.5 fields per farmer with groundwater irrigation. From Eqs. (1) and (2), it follows that the maximum number of fields, which can be irrigated without any revenue reduction, is scaled according to the number of farmers per village, $n$. For both types of irrigation, dry or wet precipitation conditions imply that one field more or less, respectively, can be irrigated without adverse effects. While any overuse of river water has an immediate effect, the effects for groundwater are rather visible over a longer perspective. On the other hand, for river water there is no memory effect as there is for groundwater.

Since overuse of resources could lower the payoff drastically, and the groundwater level might take several years to recover, some cooperation within the village and willingness to not overuse the resources is necessary to be able to win the game. However, in order to win, a farmer needs to do better than the other farmers within the village. Therefore, a farmer needs to find the subtle balance between supporting the village in not overusing the resources, while using a bit more than the other farmers within his/her village. In other words, 
Table 1. Costs and revenues for fields with different water supply. For variable explanations, see Table 2.

\begin{tabular}{lll}
\hline Type of water supply for field & Cost per field & Revenue per field \\
\hline Rainfed & 5 & 30 (in normal year) 10 (in dry year) 40 (in wet year) \\
Irrigation with river water & 20 & $100 k$ with $k=\min \left[1,1-\frac{F_{\text {river }} / n-(1.5+P)}{10-(1.5+P)}\right]$ \\
Irrigation with groundwater & $\mathrm{g}<8: 20 \mathrm{~g} \geq 8: 20+(\mathrm{g}-8)^{2}$ & 100 \\
\hline
\end{tabular}

Table 2. Explanation of variables.

\begin{tabular}{ll}
\hline Variable & Explanation \\
\hline$F_{\text {river }}$ & Number of fields with river water irrigation \\
$F_{\mathrm{gw}}$ & Number of fields with groundwater irrigation \\
$g$ & Depth to groundwater \\
$n$ & Number of farmers in a village \\
\hline$P$ & Precipitation indicator (normal year: $1 ;$ dry \\
& year: 0; wet year: 2$)$ \\
\hline
\end{tabular}

winning farmers have to find a cunning compromise between cooperation and competition within the village.

It should be noted that in the game it is assumed that there is no direct interaction between the villages in terms of water resources. The interesting effect of having several villages is that in order to win the game a farmer has not only to be best in his/her village, but at the same time needs to cooperate with the other farmers in his/her village in order to do better than the farmers in other villages. In that way, there is a competition between the different villages to use the resources as efficiently and sustainably as possible.

\subsection{Software implementation}

Irrigania has been implemented as a web application that is built in Visual Basic ASP.NET 4.0 and is running under IIS 6.0. User authentication is used to give users access to their personal pages. Two different types of users can be distinguished: teachers and students. Based on their type, users can either enter the teacher pages or the student pages. Irrigania includes two Microsoft SQL Server 2005 databases. The ASPNETDB database is used by ASP.NET to store membership data. The Irrigation game database contains teacher, game, village and farmer settings and status. HTML Help files are available, providing the user with information about the functionality of the game and the user interface.

Teachers need to register before they can use Irrigania, for which a password is needed that can be requested from the authors. After registration, a teacher can log in to his/her personal pages. Teachers can set up one or more games by specifying the villages and corresponding farmers within that game (Fig. 2). Teachers can define the length of a game, the precipitation conditions, and decide if farmers can see each other's input values. Furthermore, teachers can follow the status of a game while students are playing. In an overview, the current year, status of the villages (groundwater level and average number of fields irrigated by river water) and farmer status (water supply input values and (accumulated) balance) are given.

Players (e.g., students) obtain login details from their teacher. After logging in, students are redirected to the game page, where the decision on how to use the fields can be entered (Fig. 3). Each year, a farmer (or the player) has to submit values on how to supply his/her 10 fields with water. When all farmers have submitted their values, computations are carried out on the server, after which the game continues with the next year. During the game, farmers can see their (accumulated) balance, the current hydrological conditions, and last year's input values of the other farmers (optional). Once the game has finished, farmers can go to the results page to watch the game results. Results are published per farmer as well as per village.

\subsection{Irrigania in teaching}

In a class, it is useful to play several rounds of Irrigania, especially because the game can be played in different settings. Usually Irrigania will be played in a computer class room. Technically, Irrigania can also of course be played with students sitting at a distance from each other, although this requires some possibility for communication among the students. In versions where the students know who belongs to which village, students are allowed to talk to each other. These discussions are an important part of Irrigania. Having different villages allows the game to be played with any number of players. We found a number of 4-6 farmers in each village to generate the most interesting discussions.

Here we provide a recommended series of Irrigania games in class (about $3 \mathrm{~h}$ ) consisting of several games with different settings (each game is played over about 15 rounds/years):

1. Normal years, no information provided on the sustainable number of fields for the two irrigation types; students know who is who and see the decisions of the others after each year:

$$
\begin{aligned}
& \text { - Cooperative } \\
& \text { - Incomplete information } \\
& \text { - Students do not know the cost and profit system yet. } \\
& \text { They can develop their strategy by experimenting. }
\end{aligned}
$$




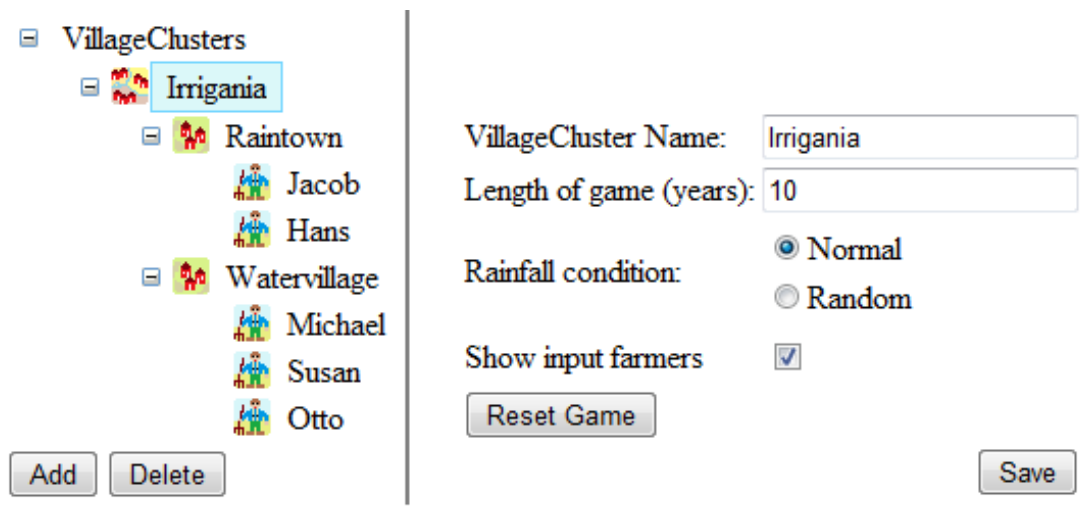

Fig. 2. Screenshot of the teacher interface when setting up a game.

2. As 1, but information is provided (i.e., Eqs. 1-2):

- Cooperative

- Complete information

- Game has changed from incomplete to complete information. Students can confirm their strategy and further improve their strategy based on the equations.

3. As 2, but students do not know who the other farmers in their village are (practically, it is most efficient to randomly assign the students to different villages in this case):

- Non-cooperative

- Complete information

- Game has changed from cooperative to noncooperative. This may lead to more selfish behavior (Hoffman et al., 1996b). A player might try to act more selfishly to benefit, at least more than the others, from over-using the resources.

4. As 2 or 3 , but with randomly varying years (dry-normalwet):

- Cooperative/Non-cooperative

- Incomplete information

- The game has changed to a game with incomplete information again (being played either cooperative or non-cooperative). Although students of course still know Eqs. (1-2), information about the yearly rainfall conditions is missing this time, making the game harder, but more realistic.

5. As any of the above, but students do not see the decisions of the others:

- Cooperative/Non-cooperative

- Complete/Incomplete information
- This option gives the players a certain amount of anonymity. Especially the cooperative version might be interesting. Trust becomes important: are farmers playing according to how they agreed to play, or will some players betray the others?

\section{Discussion}

During first tests in class, several interesting patterns could be observed. In cooperating villages, where farmers agreed to not overuse resources, farmers did best on average, but single "selfish" farmers could still win. The game is designed in such a way that the profit quickly decreases if water resources are overused and, thus, it is important for the farmers of a village, that the maximum number of fields that can be sustainably irrigated by groundwater or river water, is not exceeded. A selfish farmer might be hoping that the other farmers are taking care of restoring the water level. However, during class it was observed that, if one farmer behaves too selfishly and reproachful and words did not help, the others started to punish him/her by deliberately overusing the water resources, and the income of the entire village decreased significantly. They did this, knowing that they would also punish themselves, just to make sure that the selfish farmer did not win the game (in comparison to farmers from other villages). Such a behavior is not rational from a perspective of maximizing individual profits, but can be explained from a fairness viewpoint (see "a piece of the pie" in the above section on background in game theory). If several rounds of Irrigania are played (i.e., if Irrigania is played as a repeated game), punishment of selfish farmers might show that being selfish could result in lower payoff, and therefore makes this strategy less attractive in next rounds.

When the students did not know who the other farmers in their village were, the lack of social control leads to more overuse of the water and thus less income on average. This agrees with the common observation that social isolation leads to more individualistic behavior and less cooperation 


\section{Irrigania}

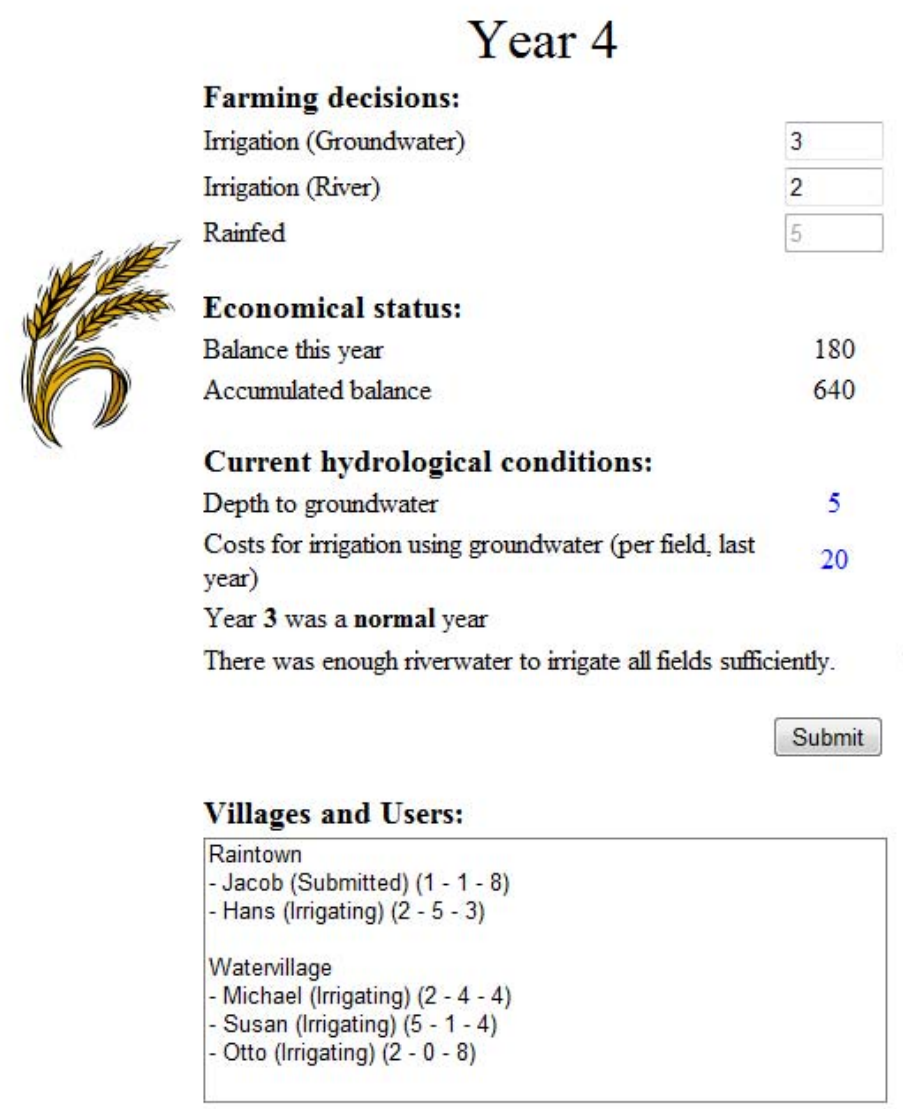

Fig. 3. Screenshot of the student interface when playing the Irrigania game.

(Nowak and Highfield, 2011). Hoffman et al. (1996) showed that, during the dictator game, higher social isolation results in more selfish behavior, and Bohnet and Frey (1999) showed that solidarity increases with decreasing social distance. However, information about the farming decisions of the other players in previous rounds might still be of help by giving a farmer some insight into the strategies of the other players. Therefore, it might be expected that there could be even more overuse of water in the case where the students cannot see the decisions of the others.

Another observation was that good decisions are more difficult with randomly varying rainfall conditions. The option to use randomly varying rainfall conditions changes the game into a game with incomplete information. For each of the three rainfall conditions, there is a separate payoff matrix. The user does not know which payoff matrix corresponds to each round, and therefore playing an optimal strategy becomes more difficult. Some players might be willing to take higher risks, whereas others might tend towards more conservative decisions.

In general, the aim of the game is to be the best farmer, i.e., make the most profit. For pedagogical reasons, however, it is recommended to not emphasize this too much. Some groups also defined other goals such as being the best village or having the winning farmer within their village. In one case, a group also decided to do all they could to "punish" a farmer who was accused of acting selfishly and ignored agreements.

All the above observations can be related to general patterns of real-world conflicts. The game provides an illustration of a tragedy-of-the-commons situation related to water management. In the short term, it can be profitable to overuse resources, especially if only a few players do so. In the long run, however, overuse leads to decreased profits for everyone. The game also demonstrates a difference between the use of water from a river and from groundwater. While water shortages might happen more quickly for river water, there is 
no year to year memory. For groundwater, on the other hand, overuse might not cause shortages directly, but once shortages become notable, it takes longer before the groundwater levels are back to normal.

Studies have shown that people only look a limited number of steps forward (iterated rationality) (Nagel, 1995). This might, to some degree, also apply for students playing Irrigania. Players might look only a few years in the future, ignoring the long-term effect of a lower groundwater level. It can be argued that this effect is even larger in reality, where objectives other than those considered in Irrigania are of importance, such as political uncertainties or varying revenues due to changing market prices. There is also a difference between the non-cooperative and the cooperative version, i.e., cooperation might influence the awareness of the students about the groundwater level and the willingness to keep the groundwater level stable compared to the case of no cooperation where the strategy might rather be to secure at least short-term profits.

All games simplify reality to a certain degree, and the real situation or conflict is reduced both in terms of considered state variables and possible handling actions in order to make the situation (or game rules) easier to understand for the players. With Irrigania, we chose a larger reduction than in most other games. The aim is that the players should fully understand the rules and their effect and make informed decisions. It is interesting that, even with such simplifications, interesting patterns can evolve when playing the game. On the other hand, there are of course important aspects of water resource sharing that are not represented in Irrigania. These include the upstream-downstream asymmetry (Janssen et al., 2011), the linkage between groundwater and river, and the conjunctive use of these resources (Kazmi et al., 2012). The latter could be considered by introducing an initial cost to be able to use groundwater or groundwater from below a certain depth. The upstream-downstream asymmetry is an important aspect in many water resource issues. It could be interesting to consider this both between and within villages. To keep the game interesting, the power of being upstream has to be balanced by some downstream power (as often found in realworld conflicts), which quickly makes the game much more complex. The interesting aspect of Irrigania is its simplicity, equal initial conditions for each player, and the conflict between competition and cooperation within a village. The fact that rules and conditions are equal for all farmers might not be realistic, but allows focus on the dynamics of sharing a common resource without the complication of different initial conditions. The interesting aspect is that, although conditions are identical, results, when playing the game, have shown large differences between farmers and villages. Also, identical conditions make it easier for the students to experience the theoretical aspects of Irrigania. In courses, it can be beneficial to compare this to games with uneven conditions, like the Irrigation Management Game (Burton, 1989, 1994), to experience the effect of inequalities.

\section{Concluding remarks}

Games related to water resource collaboration and conflicts are a valuable tool for making students and (future) professionals aware of the issues related to sharing common water resources. This is especially valuable in situations with changing conditions, where the task is to deal with new and previously not experienced situations. Predictions for the future point towards increased water scarcity, which will increase the need for cooperation in water resource management.

Irrigania is a very simple game with only few options for decisions. Still, interesting patterns evolve when playing the game in class. Similar to the games presented by Hoekstra (2012) and Rusca et al. (2012), Irrigania can be used as an additional element in courses related to water management conflicts and collaboration. While the game obviously is a vast simplification of reality, it will nevertheless help to teach about real-world water resources challenges. Differences to real-world problems, like the upstream-downstream asymmetry that is not represented in the game, can (and should) be discussed in class after playing the game. After playing the game, the students will have experienced a waterrelated example of the tragedy of the commons. They will furthermore have understood the difference between stream water resources and groundwater resources in their response to overuse and their potential recovery. They will also have seen that uncertainty about the coming weather conditions complicates optimal water resource planning. With these learning goals, the game Irrigania is a valuable complement to other course elements when teaching water resource conflicts and collaborations.

Acknowledgements. We thank our students for participating in testing the game and the reviewers Maurits Ertsen and Arjen Hoekstra for their helpful comments. As a response to one comment by Maurits Ertsen, we reanalyzed the effects of the equation defining the revenue of river-irrigated fields and realized that our original formulation could be improved. We also thank Tracy Ewen for valuable comments to improve the English.

Edited by: T. Wagener

\section{References}

Bohnet, I. and Frey, B. S.: The sound of silence in prisoner's dilemma and dictator games, J. Econ. Behav. Organ., 38, 43-57, 1999.

Burton, M. A.: Experiences with the irrigation management game, Irrigation and drainage systems, Irrigation and drainage system, 3, 217-228, 1989

Burton, M. A.: The irrigation management game: a role playing exercise for training in irrigation management, Irrigation and drainage systems, 7, 305-318, 1994. 
Camerer, C.: Behavioral game theory: experiments in strategic interaction, Princeton University Press, Princeton, xv, 550 pp., 2003.

Deltares: World Water Game, http://www.wldelft.nl/soft/wwg/, (last access: 28 June 2012), 2012.

Douven, W., Mul, M. L., Álvarez, B. F., Son, L. H., Bakker, N., Radosevich, G., and van der Zaag, P.: Enhancing capacities of riparian professionals to address and resolve transboundary issues in international river basins: experiences from the Lower Mekong River Basin, Hydrol. Earth Syst. Sci. Discuss., 9, 38133849, doi:10.5194/hessd-9-3813-2012, 2012.

FOEN: Der Umgang mit Wasser - mehr als ein Spiel, http:// www.bafu.admin.ch/wassernutzung/07805/, (last access: 28 June 2012), 2012.

Hardin, G.: Tragedy of Commons, Science, 162, 1243-1248, 1968.

Hellweger, F. L. and D'Artista, B. R.: Urban hydrology in a computer game?, Environ. Modell. Softw., 22, 1679-1684, doi:10.1016/j.envost.2006.09.004, 2007.

Hoekstra, A. Y.: Computer-supported games and role plays in teaching water management, Hydrol. Earth Syst. Sci., in review, 2012.

Hoffman, E., McCabe, K. A., and Smith, V. L.: On expectations and the monetary stakes in ultimatum games, Int. J. Game Theory, 25, 289-301, 1996.

Janssen, M. A., Anderies, J. M., and Cardenas, J. C.: Head-enders as stationary bandits in asymmetric commons: Comparing irrigation experiments in the laboratory and the field, Ecol. Econ., 70, 1590-1598, 2011.

Jones, N.: Video game: Playing with the planet, Nature Clim. Change, 1, 17-18, 2011.

Kahneman, D., Knetsch, J. L., and Thaler, R. H.: Fairness and the Assumptions of Economics, J. Bus., 59, S285-S300, 1986.

Kazmi, S. I., Ertsen, M. W., and Asib, M. R.: The impact of conjunctive use of canal and tube well water in Lagar irrigated area, Pakistan, Phys. Chem. Earth, doi:10.1016/j.pce.2012.01.001, in press, 2012.
Ledyard, J. O.: Public goods: a survey of experimental research, in: The Handbook of Experimental Economics, edited by: Kagel, J. H. and Roth, A. E., Princeton University Press, Princeton, 111$251,1995$.

List, J. A. and Cherry, T. L.: Learning to accept in ultimatum games: Evidence from an experimental design that generates low offers, Exp. Econ., 3, 11-29, 2000.

Madani, K.: Game theory and water resources, J. Hydrol., 381, 225 238, doi:10.1016/j.jhydrol.2009.11.045, 2010.

Magombeyi, M. S., Rollin, D., and Lankford, B.: The river basin game as a tool for collective water management at community level in South Africa, Phys. Chem. Earth, 33, 873-880, 2008.

Maier, H. R.: Meeting the challenges of engineering education via online roleplay simulations, Eng. Education, 13, 31-39, 2007.

Nagel, R.: Unraveling in guessing games: An experimental study, Am. Econ. Rev., 85, 1313-1326, 1995.

Nash, J.: Non-Cooperative Games, Ann. Math., 54, 286-295, 1951.

Nowak, M. A. and Highfield, R.: SuperCooperators: altruism, evolution, and why we need each other to succeed, 1st Free Press hardcover ed., Free Press, New York, xix, 330 pp., 2011.

Osborne, M. J. and Rubinstein, A.: A course in game theory, MIT Press, Cambridge, Mass., xv, 352 pp., 1994.

Rajabu, K. R. M.: Use and impacts of the river basin game in implementing integrated water resources management in Mkoji sub-catchment in Tanzania, Agr. Water Manage., 94, 63-72, doi:10.1016/j.agwat.2007.08.010, 2007.

Rusca, M., Heun, J., and Schwartz, K.: Water management simulation games and the construction of knowledge, Hydrol. Earth Syst. Sci. Discuss., 9, 3063-3085, doi:10.5194/hessd-9-30632012, 2012.

Varzaly, J. A. and Baron, J. A.: Innovating corporate governance teaching through online scenario-based learning, Internat. Rev. Business Res. Papers, 5, 156-159, 2009. 